\title{
Resistance Mechanisms and the Future of Bacterial Enoyl-Acyl Carrier Protein Reductase (Fabl) Antibiotics
}

\author{
Jiangwei Yao and Charles O. Rock \\ Department of Infectious Diseases, St. Jude Children's Research Hospital, Memphis, Tennessee 38105 \\ Correspondence: charles.rock@stjude.org
}

\begin{abstract}
Missense mutations leading to clinical antibiotic resistance are a liability of single-target inhibitors. The enoyl-acyl carrier protein reductase (Fabl) inhibitors have one intracellular protein target and drug resistance is increased by the acquisition of single-base-pair mutations that alter drug binding. The spectrum of resistance mechanisms to Fabl inhibitors suggests criteria that should be considered during the development of single-target antibiotics that would minimize the impact of missense mutations on their clinical usefulness. These criteria include high-affinity, fast on/off kinetics, few drug contacts with residue side chains, and no toxicity. These stringent criteria are achievable by structure-guided design, but this approach will only yield pathogen-specific drugs. Single-step acquisition of resistance may limit the clinical application of broad-spectrum, single-target antibiotics, but appropriately designed pathogen-specific antibiotics have the potential to overcome this liability.
\end{abstract}

$T^{\mathrm{h}}$ he emergence of resistance to most clinically deployed antibiotics has stimulated considerable interest in developing new therapeutics. Bacterial fatty acid biosynthesis is an energyintensive process that is essential for the formation of biological membranes (Zhang and Rock 2008). The importance of the pathway in bacterial physiology is highlighted by the existence of multiple natural products that target different points in fatty acid biosynthesis (Heath et al. 2001; Parsons and Rock 2011). These developments have led to a significant effort in academia and industry to develop antibiotics that target individual proteins in the fatty acid biosynthetic pathway (Campbell and Cronan 2001; Zhang et al. 2006). One concern about drugs that target fatty acid synthesis is that fatty acids are abundant in the mammalian host, raising the concern that fatty acid synthesis inhibitors would be bypassed in vivo (Brinster et al. 2009). Although all bacteria studied are capable of incorporating extracellular fatty acids into their membranes, recent research shows that exogenous fatty acids cannot circumvent the inhibition of fatty acid synthesis in many major pathogens (Parsons et al. 2011; Yao and Rock 2015).

A greater concern is the fact that fatty acid synthesis inhibitors are designed to target individual steps in the pathway. Historically successful antibiotics used as monotherapy have multiple cellular targets (Silver 2011, 2007). Multitarget antibacterials are not subject to re-

Editors: Lynn L. Silver and Karen Bush

Additional Perspectives on Antibiotics and Antibiotic Resistance available at www.perspectivesinmedicine.org

Copyright (C) 2016 Cold Spring Harbor Laboratory Press; all rights reserved; doi: 10.1101/cshperspect.a027045 Cite this article as Cold Spring Harb Perspect Med 2016;6:a027045 
sistance arising from single missense mutations that can render the drug clinically useless in a single step. These considerations led to the "multitarget hypothesis," which posits that antibiotics with multiple cellular targets are superior to single-target drugs because of their ability to avoid single-step acquisition of resistance (Silver 2011, 2007). Missense mutations occur at frequencies approximating the error rate in DNA replication of about one in $10^{9}$ cells, but environmental stresses can increase the mutation rate (Meyerovich et al. 2010). This aspect of bacterial physiology creates a reservoir of altered proteins in the bacterial population that leads to the emergence of resistant bacteria. If the resistance-causing missense mutation is a polymorphism that is normally observed in the environmental bacterial population, the evolution of resistance would be accelerated. Thus, a major liability of drugs with a single cellular target is the potential for the rapid evolution of clinical resistance.

This review focuses on a drug target in bacterial fatty acid synthesis that has received considerable attention. This target is the enoyl-acyl carrier protein (ACP) reductase (FabI) of bacterial fatty acid synthesis. FabI inhibitors are directed against a single cellular target and are subject to resistance arising from the acquisition of single-point mutations in the fabI gene. The extensive research on the mechanisms of acquired resistance to FabI-directed antibiotics coupled with insights from the clinical experience with the drugs provides a case study to evaluate the relevance of missense mutations to the utility of single-target drugs. Taken together, the experience with FabI inhibitors suggests criteria that should be considered in the development of single-target antibiotics to minimize or prevent the single-step evolution of clinical resistance.

\section{ENOYL-ACP REDUCTASE (Fabl) INHIBITORS}

Each of the enzymatic steps in bacterial fatty acid synthesis (FASII) is essential so, in principle, each is a candidate for drug discovery. However, research has focused on those enzymes that catalyze key regulatory steps in the pathway (Parsons and Rock 2011). The enoyl-acyl carrier protein reductase (FabI) catalyzes the reduction of the trans-2-enoyl-ACP to acyl-ACP using $\mathrm{NAD}(\mathrm{P}) \mathrm{H}$ in the last step of the elongation cycle of fatty acid synthesis (Parsons and Rock 2013). Because the preceding step is an equilibrium enzyme, FabI activity is responsible for pulling each cycle of elongation to completion (Heath and Rock 1995, 1996). Thus, FabI is a rate-controlling step in fatty acid elongation, providing the solid rationale for targeting this enzyme.

FabI therapeutics provide an interesting case study in bacterial-resistance mechanisms against single-target inhibitors. There are three types of FabI inhibitors (Fig. 1). Isoniazid is the example of a bisubstrate inhibitor that is in clinical use for the treatment of Mycobacterium tuberculosis. Isoniazid is a prodrug with a complex mode of activation (Fig. 1A) and there is a complex array of isoniazid-resistance mechanisms. Triclosan and its closely related derivatives bind the $\mathrm{NAD}(\mathrm{P})-$ FabI product complex (Fig. 1B), whereas the AFN-1252 (Debio-1452) and CG400549 inhibitors bind to the NAD(P)HFabI substrate complex (Fig. 1C). In both cases, resistance arises from missense mutations in the fabI gene, which leads to altered FabI proteins. Initially, it was thought that FabI inhibitors were broad-spectrum antibiotics because triclosan inhibits the growth of all bacteria. Subsequently, it was discovered that many Firmicutes do not have a FabI, but rather use a flavoprotein reductase called FabK to reduce enoyl-ACP (Heath and Rock 2000). The ability of triclosan to potently inhibit the growth of bacteria that depend on FabK is attributed to triclosan acting on other, yet to be identified, cellular target(s) (Heath and Rock 2000; Marrakchi et al. 2003). Also, some bacteria contain FabL or FabV enoylACP reductases that are sufficiently different from FabI to render organisms expressing these enzymes refractory to therapeutics designed against FabI (Heath et al. 2000; Massengo-Tiasse and Cronan 2008; Zhu et al. 2010). Thus, FabI inhibitors target a select group of pathogens.

\section{Bisubstrate Fabl Inhibitors}

Isoniazid is a frontline medication for the treatment of M. tuberculosis (Pinto and Menzies 
Genetic Resistance to Fabl Inhibitors

A<smiles>NNC(=O)c1ccncc1</smiles>

Bisubstrate Fabl inhibitor

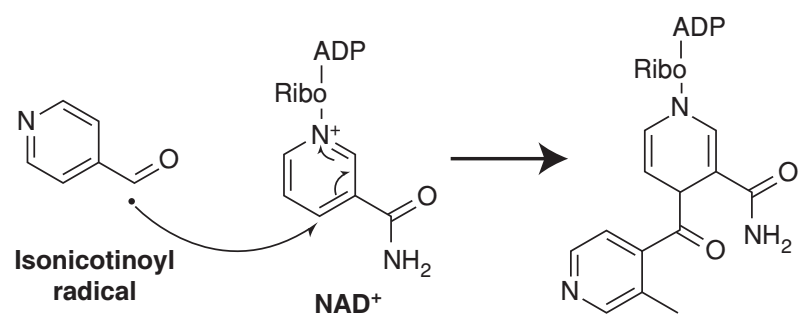

Isoniazid-NAD

B Inhibitors binding to the NAD(P)-enzyme complex<smiles>Oc1cc(Cl)ccc1Oc1ccc(Cl)cc1Cl</smiles>

Triclosan<smiles>CCc1ccc(Oc2ccccc2)c(O)c1</smiles>

5-ethyl-2-phenoxylphenol<smiles>Oc1cc(Cl)ccc1Oc1ccccc1</smiles>

5-chloro-2-phenoxylphenol<smiles>CCc1cc(O)c(Oc2ccc(C(N)=O)cc2F)cc1F</smiles>

MUT0563999<smiles>Cc1c(N)cccc1Cn1ccc(OCCc2cccs2)cc1=O</smiles>

C Inhibitors binding to the $\mathrm{NAD}(\mathrm{P}) \mathrm{H}-\mathrm{enzyme}$ complex<smiles>Cc1c(CN(C)C(=O)/C=C/c2cnc3c(c2)CCC(=O)N3)oc2ccccc12</smiles>

AFN-1252<smiles>Cc1c(CN(C)C(=O)/C=C/c2cnc3[nH]c(=O)c(C(=O)NCCN(C)C)cc3c2)c2ccccc2n1C</smiles>

CG400462

Figure 1. Structures of enoyl-ACP reductase inhibitors. (A) The mechanism of activating isoniazid, the prodrug, into the covalent isoniazid-NAD adduct, the slow-binding bisubstrate inhibitor of M. tuberculosis InhA (FabI). $(B)$ Inhibitors that bind to the $\mathrm{NAD}(\mathrm{P})$-FabI product complex. Triclosan is the prototypical inhibitor in this class. These compounds are slow-binding inhibitors. $(C)$ Inhibitors that binds to the NAD $(\mathrm{P}) \mathrm{H}-\mathrm{FabI}$ substratebinding complex of FabI. The scaffold for these two inhibitors was discovered through high-throughput screening against Staphylococcus aureus FabI. These compounds are high-affinity, fast on/off inhibitors.

2011). Daily regimens of isoniazid for 9 months is a standard treatment for latent $M$. tuberculosis infections, and isoniazid in combination with other drugs, such as rifampin, ethambutol, or pyrazinamide, is the standard treatment for active $M$. tuberculosis infections. Isoniazid was first synthesized in 1912, and shown to be effective against $M$. tuberculosis in the 1950s (Bernstein et al. 1952). The mode of isoniazid inhibition has a controversial history, with disruption of cell permeability, inhibition of DNA synthesis, altered NAD metabolism, and inhibi- 
tion of mycolic acid biosynthesis, all proposed as potential mechanisms of action (Vilchèze and Jacobs 2007). Vilchèze et al. (2006) showed that a point mutation in the M. tuberculosis enoylACP reductase InhA confers resistance to isoniazid and rescued mycolic acid biosynthesis, definitively establishing the $M$. tuberculosis enoyl-ACP reductase InhA as the relevant target of isoniazid (Vilchèze et al. 2006).

M. tuberculosis synthesizes mycolic acids, a family of complex, long-chain fatty acids, via two carbon elongations similarly to how other bacteria synthesize fatty acids via the FASII system (Marrakchi et al. 2014). Mycolic acid synthesis is essential in M. tuberculosis (Marrakchi et al. 2014) just as fatty acid synthesis is essential in other bacteria (Rock and Jackowski 2002). The M. tuberculosis inhA encodes for the enoyl-ACP reductase involved in mycolic acid synthesis and is homologous to the FabI of FASII (Quemard et al. 1995). Isoniazid is a prodrug, complicating the spectrum of potential resistance mutations. The $M$. tuberculosis catalase-peroxidase enzyme KatG activates isoniazid into an isonicotinoyl radical that covalently interacts with NAD to form an isoniazid-NAD covalent adduct (Fig. 1A) (Vilchèze and Jacobs 2007). The isoniazid-NAD adduct is a slowbinding inhibitor of InhA (Rawat et al. 2003).

M. tuberculosis resistance to isoniazid is well studied with hundreds of publications that are reviewed in depth elsewhere (Hazbón et al. 2006; Seifert et al. 2015). Although the mechanism of a small percent of isoniazid-resistant, clinically isolated specimens are unknown, all known mechanisms of resistance are related to changing the rate of formation of the isoniazidNAD covalent adduct, increasing the expression of InhA, or decreasing the affinity of InhA for the isoniazid-NAD adduct. The most frequent isoniazid resistance mechanism is mutation in the 315 th amino acid in the $k a t G$ gene found in $64.2 \%$ of resistance specimens (Seifert et al. 2015). Of these kat $G$ mutations, $95.3 \%$ cause a serine-to-threonine mutation. The rest of the mutations cause amino acid changes to asparagine $(3.6 \%)$, isoleucine $(0.5 \%)$, arginine $(0.4 \%)$, and glycine $(0.2 \%)$. The KatG(S315T) mutant enzyme does not suffer defects in the catalase or peroxidase activity, but rather has decreased rate for the formation of the isoniazid-NAD adduct (Wengenack et al. 1998). The KatG(S315T) mutant appears to have a small growth defect, with a doubling time of $19.1 \mathrm{~h}$ versus $14.3 \mathrm{~h}$ for the Erdman laboratory strain and $15.8 \mathrm{~h}$ for the $\mathrm{H} 37 \mathrm{Rv}$ laboratory strain (O'Sullivan et al. 2010). Epidemiological studies found that the KatG(S315T) mutant leads to secondary cases of tuberculosis as often as the isoniazid-susceptible strains, consistent with the fitness defect having a minor impact on virulence (van Soolingen et al. 2000). The other mutations to the KatG protein associated with isoniazid resistance occur at lower frequencies and the molecular mechanism(s) of resistance are not characterized.

The second-most-common isoniazid-resistance mechanism is mutations in the promoter region (-15) of the inhA gene. The change from a cytosine to a thymidine (19.2\%) (Seifert et al. 2015 ) correlates with a 20 -fold increase in inhA mRNA levels (Vilchèze et al. 2006). The inhA-15 mutants showed no statistically significant change in growth rate (O'Sullivan et al. 2010). Other mutations $(-8,-17$, and -47) in other locations within the inhA promoter have also been associated with resistance (Seifert et al. 2015) and are anticipated to also cause the up-regulation of inhA expression, although definitive experiments are needed. Mutations in the InhA protein itself are found in isoniazid-resistant M. tuberculosis, although the frequency observed in clinically resistant samples is low (Seifert et al. 2015). The most frequent (1.2\%) and best-characterized mutation is InhA (S94A), and this mutation reduces the affinity of the isoniazid-NAD adduct to $323 \pm 41 \mathrm{~nm}$ from $19 \pm 10 \mathrm{~nm}$ for the wild-type (Vilchèze et al. 2006). Crystallographic studies found that the loss of the serine residue caused the movement of an ordered water molecule that disrupted the polar interactions with the isoniazid-NAD adduct (Vilchèze et al. 2006). Mutations in other residues of InhA, including residues Gly3, Ile21, Ala190, Ala194, and Ile258, have been found. Three of these interact with the isoniazidNAD complex and the others do not (Fig. 2A). How mutations that do not directly contact the 


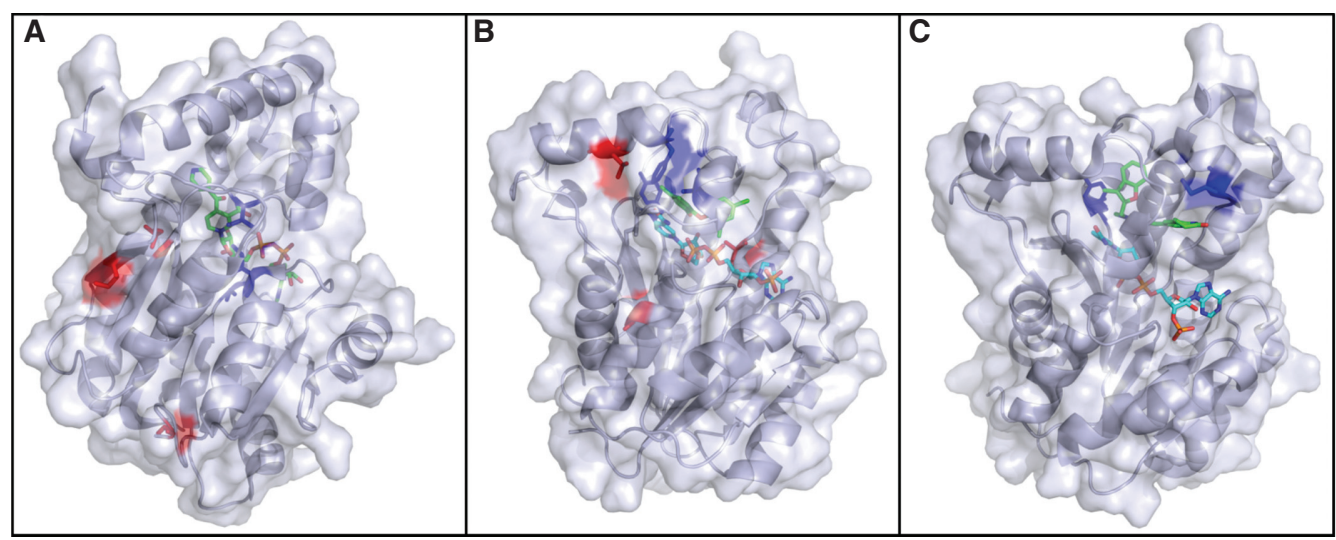

Figure 2. The locations of missense mutations in FabI conferring resistance against the three classes of FabI inhibitors are mapped onto the respective drug-protein complex structures. The respective protein structures are represented as a silver cartoon model overlaid with a transparent silver protein surface. Mutations in residues that directly interact with the inhibitor are shown in stick representation and colored blue. Mutations in residues that are not directly interacting with the inhibitor are also shown in stick representations and are colored red. The inhibitor carbons are green, nitrogens are blue, oxygens are red, and chlorines are green. The NAD $(\mathrm{P})$ carbons are cyan, phosphorus is orange, nitrogens are blue, and oxygens are red. $(A)$ The isoniazid-NAD-InhA ternary complex structure (M. tuberculosis) (PDB: 2NV6). (B) The triclosan-NADP-FabI ternary complex structure (S. aureus) (PDB: 4ALI). (C) The AFN-1252-NADPH-FabI ternary complex structure (S. aureus) (PDB: 4FS3).

bisubstrate drug impact resistance remain largely undefined (Seifert et al. 2015).

Mutations in other genetic locations are associated with isoniazid resistance and include mutations in the sigma factor SigI (Lee et al. 2012), mutations in activators or regulators of NADH/NAD metabolism (Vilchèze et al. 2005), and mutations within the ahpC-oxyR intergenic region (Seifert et al. 2015). The isoniazid resistance of the $\Delta$ sigI mutant is caused by the down-regulated expression of katG (Lee et al. 2012) and, thus, the mutation confers resistance by decreasing the rate of isoniazid-NAD formation. Although KatG catalase production is decreased in the $\Delta$ sigI mutant, this mutant is not attenuated in cell culture infections and is actually hypervirulent in mice (Lee et al. 2012). The prevalence of this mutation is not known because the association of SigI with isoniazid resistance was only recently discovered. Mutations that alter $\mathrm{NADH} / \mathrm{NAD}$ metabolism cause resistance through changing the concentration of the substrates necessary for the formation of the active drug (Vilchèze et al. 2005), and also give rise to resistance to ethionamide, a drug used against multidrug-resistant $M$. tuberculosis. However, this mutation was found at low frequencies among clinical samples (Hazbón et al. 2006). The mechanism by which mutations in the ahpC-oxyR intergenic region are associated with resistance in $M$. tuberculosis remains unclear (Sreevatsan et al. 1997). However, in Escherichia coli, deletion of $o x y R$, a regulator of hydrogen peroxide inducible genes, causes sensitivity to isoniazid (Rosner and Storz 1994).

How isoniazid is deployed against latent and active M. tuberculosis highlights the practical implications of drug resistance in antibiotic therapy. Because of the mode of action of isoniazid, a host of different mutations in different pathways triggers resistance, giving rise to an elevated rate of missense-resistance mutations against isoniazid as high as one in $10^{8}$ (David 1970). Furthermore, the two most prevalent resistance mechanisms against isoniazid both require only a single-base-pair mutation and impose a minimal fitness cost to the mutant strain. Isoniazid is deployed as a monotherapy to treat latent $M$. tuberculosis, but the frequency of resistance mutations renders isoniazid inef- 
fective as a monotherapy against active $M$. tuberculosis because each cavity contains more than $10^{8}$ bacteria (Pinto and Menzies 2011).

Inhibitors Binding to the $\mathrm{NAD}(\mathrm{P})-\mathrm{Fabl}$ Product Complex

Triclosan is a broad-spectrum antibacterial and antifungal agent added to a variety of consumer products, including soaps, mouthwashes, and antiseptics (Russell 2004). Triclosan has two modes of action. First, triclosan is a nonspecific biocide that disrupts cell physiology by a poorly defined mechanism (Russell 2003). Second, triclosan is a slow-binding FabI inhibitor that binds to the FabI-NAD $(\mathrm{P})$ complex of the enzyme formed after acyl-ACP product release (Heath et al. 1998, 1999; McMurry et al. 1998a). For bacteria that do not encode a FabI enoyl-ACP reductase, such as Streptococcus pneumoniae, triclosan inhibition is through the nonspecific biocide mechanism (Heath and Rock 2000). For bacteria that encode for a triclosan-sensitive FabI, such as E. coli or S. aureus, the minimal inhibitory concentration (MIC) for FabI inhibition occurs at $\mathrm{ng} / \mathrm{ml}$ concentration, whereas the inhibitory concentration of triclosan mediated by the nonspecific biocide mechanism occurs at $\mu \mathrm{g} / \mathrm{ml}$ concentrations (Heath et al. 1999; Heath and Rock 2000; Parsons et al. 2011; Yao et al. 2013).

The widespread inclusion of triclosan in consumer products along with the environmental persistence of triclosan has created an interesting environment for resistance development. Triclosan resistance is well studied in E. coli and S. aureus, and many missense mutants have been isolated (Fig. 2B). In E. coli, resistance to triclosan is mediated through the G93V missense mutation in the fabI gene and by accelerating efflux through the increased expression of marA, soxS, acrAB, and acrF. Triclosan is 64 times less potent against the $E$. coli FabI(G93V) mutant strain compared with the wild-type strain (Heath et al. 1999). Structurally, the C $\gamma$ of the Gly93 residue is $3.9 \AA$ away from the chlorine on the phenyl ring of triclosan (Levy et al. 1999; Stewart et al. 1999). Mutating the glycine to valine is predicted to introduce a side chain that causes a steric clash with the chlorine atom in triclosan, decreasing the binding affinity. The FabI(G93V) mutation imposes a minor fitness cost to growth (Curiao et al. 2015). Elevated expression of the marA, soxS, $a c r A B$, and $a c r F$ genes leads to increased efflux, which is a second mechanism for triclosan resistance in E. coli (McMurry et al. 1998b; Curiao et al. 2015). Increased expression of these genes did not impose an observable fitness cost to the strains (Curiao et al. 2015). The overexpression of efflux through these genes also causes coresistance against other antibiotics, including ampicillin, tetracyclines, and fluoroquinolones (Curiao et al. 2015). No mutations in the fabI gene are observed in triclosan-resistant Klebsiella pneumoniae, and resistance was mediated through the elevated expression of the marA, soxS, acr $A B$, and acrF efflux pumps (Curiao et al. 2015).

Methicillin-resistant $S$. aureus was a major clinical concern in the last decade leading to the development of triclosan-derived FabI inhibitors targeting S. aureus (Fig. 1B). Two inhibitors, MUT056399 (Escaich et al. 2011) and CG400549 (Park et al. 2007a), have entered clinical trials, and active research is being conducted on other triclosan analogs. High-level resistance against triclosan and triclosan-derived inhibitors in $S$. aureus is mediated by mutations in the $f a b I$ gene. Missense mutations give rise to G23S, F204C, Y147H, A198G, L208F, and A95V FabI variants that confer resistance to triclosan in S. aureus (Fan et al. 2002; Brenwald and Fraise 2003). The F204L mutation was identified as resistant to CG400549 (Park et al., 2007a), and the A95V, F204S, and I193F mutations led to resistance against MUT056399 (Escaich et al. 2011). Strains expressing A95V, I193S, and F204S FabI variants are also resistant to 5-ethyl-2-phenoxyphenol and 5-chloro-2-phenoxyphenol compounds (Xu et al. 2008). Phe204, Ala198, and Tyr147 interact with the triclosan molecule, whereas direct interactions with Ala95, Ile193, Leu208, and Gly23 are absent. In particular, Gly23 is located on the surface of the protein far from the active site (Fig. 2B). Because triclosan is a slow-binding inhibitor requiring a conformational change in FabI for tight bind- 
ing, the mutations that do not directly contact the drug are likely to be modifiers of the protein conformational transition. Triclosan resistance in Staphylococcus epidermidis is mediated by similar mutations to the fabI gene, as well as the elevated expression of fabI through mutations in the putative promoter region (Skovgaard et al. 2013). However, resistance arising from alterations in gene expression are usually only a few-fold, and single-target antibiotics should be designed with sufficient potency to make these relatively minor genetic mechanisms for resistance irrelevant in the clinic.

\section{Inhibitors Binding to the $\mathrm{NAD}(\mathrm{P}) \mathrm{H}-\mathrm{Fabl}$ Substrate Complex}

Two inhibitors derived from the same scaffold, CG400462 (Park et al. 2007b) and AFN-1252 (Fig. 1C) (Karlowsky et al. 2009; Kaplan et al. 2012, 2013a), bind to the NAD(P)H-FabI substrate complex (Fig. 2C). The best studied of this class of inhibitors is AFN-1252, which has moved through phase II clinical trials. AFN-1252 was discovered through target-based screening and structure-based optimization against the $S$. aureus FabI and has no detectable mammalian toxicity (Payne et al. 2002; Karlowsky et al. 2007, 2009; Kaplan et al. 2012). Using structure-based design to optimize the inhibition of S. aureus, FabI achieves low ng/ml MICs against this pathogen (Kaplan et al. 2012). AFN1252 is a fast on/off inhibitor that binds to the FabI-NADPH complex of $S$. aureus FabI with low nanomolar affinity (Yao et al. 2013). AFN-1252 treatment causes a dose-dependent decrease in fatty acid synthesis and an accumulation of medium-chain acyl-ACP (Parsons et al. 2011; Yao et al. 2013). Exogenous fatty acids cannot save S. aureus from AFN-1252 inhibition because the inhibition of de novo fatty acid synthesis ties up all the free ACP as acylACP (Parsons et al. 2011). Extracellular fatty acids can bypass AFN-1252 inhibition only when de novo fatty acid synthesis is completely disabled using an acetyl-CoA carboxylase knockout strain (Parsons et al. 2011). The inability of acetyl-CoA carboxylase mutants to initiate fatty acid synthesis means that there are no substrates for FabI, and free ACP is available for the uptake and incorporation of exogenous fatty acids. This result illustrates that AFN-1252 does not have another cellular target (Parsons et al. 2011; Yao et al. 2013). However, S. aureus with inactivating mutations in acetyl-CoA carboxylase have significantly decreased growth rates and do not proliferate in mice demonstrating that inactivating acetyl-CoA carboxylase is not a biologically viable mechanism to bypass FabI inhibition in S. aureus (Parsons et al. 2013a).

Laboratory-directed evolution has defined the mechanisms for the development of $S$. aureus mutants resistant to AFN-1252 (Fig 2C). Three separate studies found only two missense mutations in the fabI gene that give rise to a greater than fourfold increase in resistance against AFN-1252 (Parsons et al. 2011; Kaplan et al. 2012; Yao et al. 2013). The same mutations confer resistance to CG400462 (Park et al. 2007b). The Tyr 147 residue interacts with the 3-methylbenzofuran portion of AFN-1252 (Kaplan et al. 2012), and the Y147H mutation increased the MIC from $3.9 \mathrm{ng} / \mathrm{ml}$ to $500 \mathrm{ng} / \mathrm{ml}$ (Fig. 2C) (Yao et al. 2013). However, Tyr147 is predicted to bind the thioester carboxyl of the substrate to stabilize the transition state, and $\mathrm{FabI}(\mathrm{Y} 147 \mathrm{H})$ has a greater than 10-fold decrease in catalytic activity (Yao et al. 2013). This catalytic defect is reflected in a significantly decreased growth rate of strains expressing the FabI $(\mathrm{Y} 147 \mathrm{H})$ mutant. Strains expressing FabI $(\mathrm{Y} 147 \mathrm{H})$ are cross-resistant to triclosan, with the MIC increased to $500 \mathrm{ng} / \mathrm{ml}$ from $62.5 \mathrm{ng} / \mathrm{ml}$ in the wild-type strain. Met99 interacts with the oxotetrahydronaphthyridine portion of AFN-1252. FabI(M99T) bound to AFN-1252 with a 17 -fold decrease in affinity compared with the wild-type enzyme, and the mutant strain increased the MIC from $3.9 \mathrm{ng} / \mathrm{ml}$ to $250 \mathrm{ng} / \mathrm{ml}$. This mutant enzyme has no apparent catalytic deficiency in vitro and the mutant strain does not have a growth defect. The genes encoding FASII components are up-regulated in the FabI(M99T)-expressing mutant strains, illustrating that there is a small fitness cost. Saturation mutagenesis was conducted at the Met99 residue, and the mutation 
to threonine gave the highest level of resistance. Interestingly, FabI(M99T)-expressing strains are $\sim 16$-fold more susceptible to triclosan, although the Met99 side chain does not interact with triclosan. Strains carrying either the FabI(M99T) or FabI(Y147H) mutations have an MIC that is significantly lower than the plasma concentrations of AFN-1252 that are achieved in published murine infection models (Kaplan et al. 2013b; Parsons et al. 2013b). The fitness of these two mutants in an animal model is unknown. Attempts to select for additional mutations yielding higher levels of resistance against AFN-1252 starting from these two single-point mutants were unsuccessful (Yao et al. 2013). The FabI enzyme containing both the M99Tand Y147H mutations had lower catalytic activity than the $\mathrm{Y} 147 \mathrm{H}$ mutant alone and was unable to support growth. Experiments are needed to determine whether strains harboring FabI(M99T) protein are susceptible to the doses of AFN-1252 used in the standard therapy for S. aureus infections. Drug dosing at AFN- 1252 levels required to eliminate strains with the FabI(M99T) mutation would mitigate any impact of the mutation on the therapeutic usefulness of the antibiotic.

\section{CONCLUSIONS}

The multitarget hypothesis argues that antibiotics designed against single gene targets will fail because the bacterial load is high enough in human infections to select for missense mutants that will render the antibiotic ineffective (Silver and Bostian 1993; Silver 2007, 2011). This sound reasoning argues against developing single-target inhibitors as monotherapies, but the experience with resistance profiles of FabI inhibitors suggests key drug properties that should be optimized to diminish the rapid evolution of clinical resistance in single-target inhibitors. First, it is critical that the drug have very high potency (low MIC). This high potency must be coupled with a low toxicity profile that allows clinical dosing at concentrations that exceed the amounts required to eradicate any missense mutations that may arise. The AFN-1252 case illustrates that these stringent criteria for single-target drugs can be achieved by structure-aided design. However, drugs with this high potency will necessarily be pathogen specific. Creating a broad-spectrum antibiotic requires compromising the potency against a single species to achieve broader clinical utility. This process inevitably results in lower drug potency against all species within the antibiotic spectrum. This compromised potency increases the potential for single-step resistance to shift the antibiotic dose needed to cure the resistant strains to concentrations that cannot be achieved and/or tolerated. Second, the drug should be designed to minimize the number of interactions with residue side chains while preserving high-affinity binding (Fig. 2C). Each side-chain interaction provides an opportunity for a missense mutation to arise that will compromise drug binding. One potential exception would be those side chains that are important for catalysis. If the drug target is a rate-controlling step in the pathway, then missense mutations in catalytic residues will introduce a fitness cost to the cells. These considerations mean that the experimental evaluation of drug resistance must be an early and integral part of the antibiotic development processes rather than something that is evaluated at the end.

The analysis of the resistance profiles of FabI inhibitors also reveals a liability associated with slow-binding inhibitors. These inhibitors have slow off rates caused by protein conformationdependent transitions that lead to tight drug binding. The improvements in potency and target selectivity provided by slow-binding inhibitors have been clearly articulated (Lu and Tonge 2010; Walkup et al. 2015); however, if the slowbinding conformational change is critical to drug efficacy, resistance mutations will arise at residue positions that are key to initiating and/ or maintaining the desired conformational change. The experience with triclosan and isoniazid, two slow-binding FabI inhibitors, reveals this vulnerability (Fig. 2A,B). Of the triclosan-resistant missense mutations discussed in this review, three of seven occur at residues with side chains that contact the drug, whereas the other four are found at other locations. Many isoniazid-resistant InhA mutations (three 
of six) are located in positions that do not directly contact the drug. These mutations are located in protein sequences that are predicted to participate in the conformational change responsible for its slow-binding characteristics. The spectrum of resistance mutations to isoniazid and triclosan is in sharp contrast to the number of mutations conferring AFN-1252 resistance. AFN-1252 is a fast, tight-binding inhibitor, and the only mutations that have been detected are in the two residues with side chains that contact the drug (Yao et al. 2013). Thus, advantages gained in optimizing the slow-binding characteristics of an antibiotic are offset by the higher number of missense mutations that can arise with the potential to limit the clinical usefulness of the drug.

Recent advances in human gut microbiome research suggest that taking a pathogen selective approach has merit. Broad-spectrum antibiotic treatment causes severe disturbances to the human microbiome and has been linked to both short-term health consequences such as reduced infection resistance, as well as long-term health consequences such as the development of allergic and metabolic diseases (Blaser and Falkow 2009; Croswell et al. 2009). In particular, broadspectrum antibiotic treatment early in life is highly associated with the development of type 2 diabetes (Boursi et al. 2015), obesity (Cho et al. 2012), and celiac disease later in life (Mårild et al. 2013). One of the most difficult-to-treat infections, Clostridium difficile colitis, also arises once treatment with broad-spectrum antibiotics eliminates the gut microbiome (Buffie et al. 2012). In this respect, FabI is a fascinating target. Broad-spectrum antibiotics cause a severalthousand-fold reduction in the gut microbial load (Croswell et al. 2009). Many important species of the gut microbiome (Firmicutes) are predicted to be immune to FabI inhibitors because they encode for a different enoyl-ACP reductase isoform (FabK) (Yao and Rock 2015). A number of pathogens with significant medical impact do encode a FabI, including Neisseria, various bacteria from the class Gammaproteobacteria (Enterobacteriaceae, Pseudomonas, Salmonella, Shigella, Acinetobacter), Campylobacter, S. aureus, and Mycobacterium species. It will be impor- tant to experimentally test the prediction that FabI inhibitors will have minimal impact on the gut microbiome, but the deployment of potent, pathogen-selective antibiotics is clearly predicted to minimize collateral damage to the host microbiome.

\section{ACKNOWLEDGMENTS}

This work is supported by National Institutes of Health Grants GM034496 (C.O.R.), Cancer Center Support Grant CA21765, and the American Lebanese Syrian Associated Charities. A portion of our laboratory research is funded by Debiopharm Group.

\section{REFERENCES}

Bernstein J, Lott WA, Steinberg BA, Yale HL. 1952. Chemotherapy of experimental tuberculosis. V: Isonicotinic acid hydrazide (nydrazid) and related compounds. Am Rev Tuberc 65: 357-364.

Blaser MJ, Falkow S. 2009. What are the consequences of the disappearing human microbiota? Nat Rev Micro 7: 887894.

Boursi B, Mamtani R, Haynes K, Yang YX. 2015. The effect of past antibiotic exposure on diabetes risk. Eur J Endocrinol 172: 639-648.

Brenwald NP, Fraise AP. 2003. Triclosan resistance in methicillin-resistant Staphylococcus aureus (MRSA). J Hosp Infect 55: 141-144.

Brinster S, Lamberet G, Staels B, Trieu-Cuot P, Gruss A, Poyart C. 2009. Type II fatty acid synthesis is not a suitable antibiotic target for Gram-positive pathogens. $\mathrm{Na}$ ture 458: 83-86.

Buffie CG, Jarchum I, Equinda M, Lipuma L, Gobourne A, Viale A, Ubeda C, Xavier J, Pamer EG. 2012. Profound alterations of intestinal microbiota following a single dose of clindamycin results in sustained susceptibility to Clostridium difficile-induced colitis. Infect Immun 80: 62-73.

Campbell JW, Cronan JE Jr. 2001. Bacterial fatty acid biosynthesis: Targets for antibacterial drug discovery. Annu Rev Microbiol 55: 305-332.

Cho I, Yamanishi S, Cox L, Methe BA, Zavadil J, Li K, Gao Z, Mahana D, Raju K, Teitler I, et al. 2012. Antibiotics in early life alter the murine colonic microbiome and adiposity. Nature 488: 621-626.

Croswell A, Amir E, Teggatz P, Barman M, Salzman NH. 2009. Prolonged impact of antibiotics on intestinal microbial ecology and susceptibility to enteric Salmonella infection. Infect Immun 77: 2741-2753.

Curiao T, Marchi E, Viti C, Oggioni MR, Baquero F, Martinez JL, Coque TM. 2015. Polymorphic variation in susceptibility and metabolism of triclosan-resistant mutants of Escherichia coli and Klebsiella pneumoniae clinical strains obtained after exposure to biocides and antibiotics. Antimicrobiol Agents Chem 59: 3413-3423. 
J. Yao and C.O. Rock

David HL. 1970. Probability distribution of drug-resistant mutants in unselected populations of Mycobacterium tuberculosis. Appl Microbiol 20: 810-814.

Escaich S, Prouvensier L, Saccomani M, Durant L, Oxoby M, Gerusz V, Moreau F, Vongsouthi V, Maher K, Morrissey I, et al. 2011. The MUT056399 inhibitor of FabI is a new antistaphylococcal compound. Antimicrob Agents Chemother 55: 4692-4697.

Fan F, Yan K, Wallis NG, Reed S, Moore TD, Rittenhouse SF DeWolf JW Jr, Huang J, McDevitt D, Miller WH, et al. 2002. Defining and combating the mechanisms of triclosan resistance in clinical isolates of Staphylococcus aureus. Antimicrob Agents Chemother 46: 3343-3347.

Hazbón MH, Brimacombe M, Bobadilla del Valle M, Cavatore M, Guerrero MI, Varma-Basil M, Billman-Jacobe H, Lavender C, Fyfe J, García-García L, et al. 2006. Population genetics study of Isoniazid resistance mutations and evolution of multidrug-resistant Mycobacterium tuberculosis. Antimicrobiol Agents Chem 50: 2640-2649.

Heath RJ, Rock CO. 1995. Enoyl-acyl carrier protein reductase ( $f a b I$ ) plays a determinant role in completing cycles of fatty acid elongation in Escherichia coli. J Biol Chem 270: $26538-26542$.

Heath RJ, Rock CO. 1996. Regulation of fatty acid elongation and initiation by acyl-acyl carrier protein in Escherichia coli. J Biol Chem 271: 1833-1836.

Heath RJ, Rock CO. 2000. A triclosan-resistant bacterial enzyme. Nature 406: 145-146.

Heath RJ, Yu YT, Shapiro MA, Olson E, Rock CO. 1998. Broad spectrum antimicrobial biocides target the FabI component of fatty acid synthesis. J Biol Chem 273: 30316-30321.

Heath RJ, Rubin JR, Holland DR, Zhang E, Snow ME, Rock CO. 1999. Mechanism of triclosan inhibition of bacterial fatty acid synthesis. J Biol Chem 274: 11110-11114.

Heath RJ, Su N, Murphy CK, Rock CO. 2000. The enoyl[acyl-carrier-protein] reductases FabI and FabL from $\mathrm{Ba}$ cillus subtilis. J Biol Chem 275: 40128-40133.

Heath RJ, White SW, Rock CO. 2001. Lipid biosynthesis as a target for antibacterial agents. Prog Lipid Res 40: 467497.

Kaplan N, Albert M, Awrey D, Bardouniotis E, Berman J, Clarke T, Dorsey M, Hafkin B, Ramnauth J, Romanov V, et al. 2012. Mode of action, in vitro activity, and in vivo efficacy of AFN-1252, a selective antistaphylococcal FabI inhibitor. Antimicrob Agents Chemother 56: 5865-5874.

Kaplan N, Awrey D, Bardouniotis E, Berman J, Yethon J, Pauls HW, Hafkin B. 2013a. In vitro activity (MICs and rate of kill) of AFN-1252, a novel FabI inhibitor, in the presence of serum and in combination with other antibiotics. J Chemother 25: 18-25.

Kaplan N, Garner C, Hafkin B. 2013b. AFN-1252 in vitro absorption studies and pharmacokinetics following microdosing in healthy subjects. Eur J Pharm Sci 50: 440446.

Karlowsky JA, Laing NM, Baudry T, Kaplan N, Vaughan D, Hoban DJ, Zhanel GG. 2007. In vitro activity of API1252, a novel FabI inhibitor, against clinical isolates of Staphylococcus aureus and Staphylococcus epidermidis. Antimicrob Agents Chemother 51: 1580-1581.
Karlowsky JA, Kaplan N, Hafkin B, Hoban DJ, Zhanel GG. 2009. AFN-1252, a FabI inhibitor, demonstrates a Staphylococcus-specific spectrum of activity. Antimicrob Agents Chemother 53: 3544-3548.

Lee JH, Ammerman NC, Nolan S, Geiman DE, Lun S, Guo H, Bishai WR. 2012. Isoniazid resistance without a loss of fitness in Mycobacterium tuberculosis. Nat Commun 3: 753.

Levy CW, Roujeinikova A, Sedelnikova S, Baker PJ, Stuitje AR, Slabas AR, Rice DW, Rafferty JB. 1999. Molecular basis of triclosan activity. Nature 398: 383-384.

Lu H, Tonge PJ. 2010. Drug-target residence time: Critical information for lead optimization. Curr Opin Chem Biol 14: $467-474$.

Mårild K, Ye W, Lebwohl B, Green PH, Blaser MJ, Card T, Ludvigsson JF. 2013. Antibiotic exposure and the development of coeliac disease: A nationwide case-control study. BMC Gastroenterol 13: 109.

Marrakchi H, DeWolf C Jr, Quinn C, West J, Polizzi BJ, So CY, Holmes DJ, Reed SL, Heath RJ, Payne DJ, et al. 2003. Characterization of Streptococcus pneumoniae enoyl-[acyl carrier protein] reductase (FabK). Biochem J 370: 1055-1062.

Marrakchi H, Lanéelle MA, Daffé M. 2014. Mycolic acids: Structures, biosynthesis, and beyond. Chem Biol 21: 6785 .

Massengo-Tiasse RP, Cronan JE. 2008. Vibrio cholerae fab V defines a new class of enoyl acyl-carrier-protein reductase. J Biol Chem 283: 1308-1316.

McMurry LM, Oethinger M, Levy S. 1998a. Triclosan targets lipid synthesis. Nature 394: 531-532.

McMurry LM, Oethinger M, Levy SB. 1998b. Overexpression of marA, soxS, or $a c r A B$ produces resistance to triclosan in laboratory and clinical strains of Escherichia coli. FEMS Microbiol Lett 166: 305-309.

Meyerovich M, Mamou G, Ben-Yehuda S. 2010. Visualizing high error levels during gene expression in living bacterial cells. Proc Natl Acad Sci 107: 11543-11548.

O’Sullivan DM, McHugh TD, Gillespie SH. 2010. Mapping the fitness of Mycobacterium tuberculosis strains: A complex picture. J Med Microbiol 59: 1533-1535.

Park HS, Yoon YM, Jung SJ, Kim CM, Kim JM, Kwak JH. 2007a. Antistaphylococcal activities of CG400549, a new bacterial enoyl-acyl carrier protein reductase (FabI) inhibitor. J Antimicrob Chemother 60: 568-574.

Park HS, Yoon YM, Jung SJ, Yun IN, Kim CM, Kim JM, Kwak JH. 2007b. CG400462, a new bacterial enoyl-acyl carrier protein reductase (FabI) inhibitor. Int J Antimicrob Agents 30: 446-451.

Parsons JB, Rock CO. 2011. Is bacterial fatty acid synthesis a valid target for antibacterial drug discovery? Curr Opin Microbiol 14: 544-549.

Parsons JB, Rock CO. 2013. Bacterial lipids: Metabolism and membrane homeostasis. Prog Lipid Res 52: 249-276.

Parsons JB, Frank MW, Subramanian C, Saenkham P, Rock CO. 2011. Metabolic basis for the differential susceptibility of Gram-positive pathogens to fatty acid synthesis inhibitors. Proc Natl Acad Sci 108: 15378-15383.

Parsons JB, Frank MW, Rosch JW, Rock CO. 2013a. Staphylococcus aureus fatty acid auxotrophs do not proliferate in mice. Antimicrob Agents Chemother 57: 5729-5732. 
Parsons JB, Kukula M, Jackson P, Pulse M, Simecka JW, Valtierra D, Weiss WJ, Kaplan N, Rock CO. 2013b. Perturbation of Staphylococcus aureus gene expression by the enoyl-acyl carrier protein reductase inhibitor AFN-1252. Antimicrob Agents Chemother 57: 2182-2190.

Payne DJ, Miller WH, Berry V, Brosky J, Burgess WJ, Chen E, DeWolf JW Jr, Fosberry AP, Greenwood R, Head MS, et al. 2002. Discovery of a novel and potent class of FabIdirected antibacterial agents. Antimicrob Agents Chemother 46: 3118-3124.

Pinto L, Menzies D. 2011. Treatment of drug-resistant tuberculosis. Infect Drug Resist 4: 129-135.

Quemard A, Sacchettini JC, Dessen A, Vilchèze C, Bittman R, Jacobs WR, Blanchard JS. 1995. Enzymic characterization of the target for Isoniazid in Mycobacterium tuberculosis. Biochemistry 34: 8235-8241.

Rawat R, Whitty A, Tonge PJ. 2003. The isoniazid-NAD adduct is a slow, tight-binding inhibitor of InhA, the Mycobacterium tuberculosis enoyl reductase: Adduct affinity and drug resistance. Proc Natl Acad Sci 100: 1388113886.

Rock CO, Jackowski S. 2002. Forty years of fatty acid biosynthesis. Biochem Biophys Res Commun 292: 1155-1166.

Rosner JL, Storz G. 1994. Effects of peroxides on susceptibilities of Escherichia coli and Mycobacterium smegmatis to isoniazid. Antimicrobiol Agents Chem 38: 1829-1833.

Russell AD. 2003. Similarities and differences in the responses of microorganisms to biocides. J Antimicrob Chemother 52: 750-763.

Russell AD. 2004. Whither triclosan? J Antimicrob Chemother 53: 693-695.

Seifert M, Catanzaro D, Catanzaro A, Rodwell TC. 2015. Genetic mutations associated with isoniazid resistance in Mycobacterium tuberculosis: A systematic review. PLoS ONE 10: $\mathrm{e} 0119628$.

Silver LL. 2007. Multi-targeting by monotherapeutic antibacterials. Nat Rev Drug Discov 6: 41-55.

Silver LL. 2011. Challenges of antibacterial discovery. Clin Microbiol Rev 24: 71-109.

Silver LL, Bostian KA. 1993. Discovery and development of new antibiotics: The problem of antibiotic resistance. Antimicrob Agents Chemother 37: 377-383.

Skovgaard S, Nielsen LN, Larsen MH, Skov RL, Ingmer H, Westh H. 2013. Staphylococcus epidermidis isolated in 1965 are more susceptible to Triclosan than current isolates. PLoS ONE 8: e62197.

Sreevatsan S, Pan X, Zhang Y, Deretic V, Musser JM. 1997. Analysis of the oxyR-ahpC region in isoniazid-resistant and -susceptible Mycobacterium tuberculosis complex organisms recovered from diseased humans and animals in diverse localities. Antimicrobiol Agents Chem 41: 600606.

Stewart MJ, Parikh S, Xiao G, Tonge PJ, Kisker C. 1999. Structural basis and mechanism of enoyl reductase inhibition by triclosan. J Mol Biol 290: 859-865.

van Soolingen D, de Haas PEW, van Doorn HR, Kuijper E, Rinder H, Borgdorff MW. 2000. Mutations at amino acid position 315 of the kat $G$ gene are associated with highlevel resistance to Isoniazid, other drug resistance, and successful transmission of Mycobacterium tuberculosis in the Netherlands. J Infect Dis 182: 1788-1790.

Vilchèze C, Jacobs WR Jr. 2007. The mechanism of Isoniazid killing: Clarity through the scope of genetics. Annu Rev Microbiol 61: 35-50.

Vilchèze C, Weisbrod TR, Chen B, Kremer L, Hazbón MH, Wang F, Alland D, Sacchettini JC, Jacobs WR. 2005. Altered $\mathrm{NADH} / \mathrm{NAD}^{+}$ratio mediates coresistance to isoniazid and ethionamide in mycobacteria. Antimicrobiol Agents Chem 49: 708-720.

Vilchèze C, Wang F, Arai M, Hazbon MH, Colangeli R, Kremer L, Weisbrod TR, Alland D, Sacchettini JC, Jacobs WR. 2006. Transfer of a point mutation in Mycobacterium tuberculosis inhA resolves the target of isoniazid. Nat Med 12: 1027-1029.

Walkup GK, You Z, Ross PL, Allen EK, Daryaee F, Hale MR, O'Donnell J, Ehmann DE, Schuck VJ, Buurman ET, et al. 2015. Translating slow-binding inhibition kinetics into cellular and in vivo effects. Nat Chem Biol 11: 416-423.

Wengenack NL, Todorovic S, Yu L, Rusnak F. 1998. Evidence for differential binding of isoniazid by Mycobacterium tuberculosis KatG and the isoniazid-resistant mutant KatG(S315T). Biochemistry 37: 15825-15834.

Xu H, Sullivan TJ, Sekiguchi J, Kirikae T, Ojima I, Stratton CF, Mao W, Rock FL, Alley MR, Johnson F, et al. 2008. Mechanism and inhibition of saFabI, the enoyl reductase from Staphylococcus aureus. Biochemistry 47: 4228-4236.

Yao J, Rock CO. 2015. How bacterial pathogens eat host lipids: Implications for the development of fatty acid synthesis therapeutics. J Biol Chem 290: 5940-5946.

Yao J, Maxwell JB, Rock CO. 2013. Resistance to AFN-1252 arises from missense mutations in Staphylococcus aureus enoyl-acyl carrier protein reductase (FabI). J Biol Chem 288: 36261-36271.

Zhang YM, Rock CO. 2008. Membrane lipid homeostasis in bacteria. Nat Rev Microbiol 6: 222-233.

Zhang YM, White SW, Rock CO. 2006. Inhibiting bacterial fatty acid synthesis. J Biol Chem 281: 17541-17544.

Zhu L, Lin J, Ma J, Cronan JE, Wang H. 2010. Triclosan resistance of Pseudomonas aeruginosa PAO1 is due to FabV, a triclosan-resistant enoyl-acyl carrier protein reductase. Antimicrobiol Agents Chem 54: 689-698. 


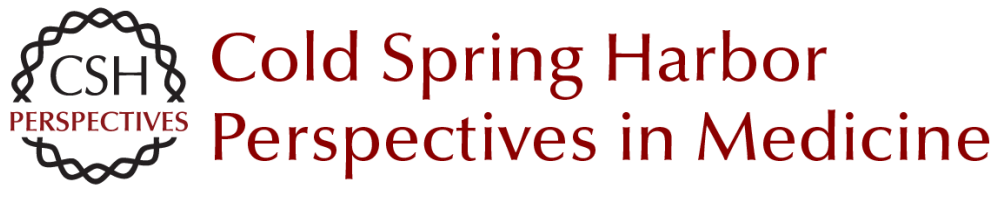

\section{Resistance Mechanisms and the Future of Bacterial Enoyl-Acyl Carrier Protein Reductase (Fabl) Antibiotics}

Jiangwei Yao and Charles O. Rock

Cold Spring Harb Perspect Med 2016; doi: 10.1101/cshperspect.a027045

Subject Collection Antibiotics and Antibiotic Resistance

Fosfomycin: Mechanism and Resistance

Lynn L. Silver

Pleuromutilins: Potent Drugs for Resistant Bugs

--Mode of Action and Resistance

Susanne Paukner and Rosemarie Riedl

Appropriate Targets for Antibacterial Drugs

Lynn L. Silver

Lincosamides, Streptogramins, Phenicols, and Pleuromutilins: Mode of Action and Mechanisms of Resistance

Stefan Schwarz, Jianzhong Shen, Kristina Kadlec, et al.

Resistance to Macrolide Antibiotics in Public Health Pathogens

Corey Fyfe, Trudy H. Grossman, Kathy Kerstein, et al.

Bacterial Protein Synthesis as a Target for

Antibiotic Inhibition

Stefan Arenz and Daniel N. Wilson

Antibacterial Antifolates: From Development through Resistance to the Next Generation

Alexavier Estrada, Dennis L. Wright and Amy C. Anderson

Antibacterial Drug Discovery Targeting the Lipopolysaccharide Biosynthetic Enzyme LpxC Alice L. Erwin
The Whys and Wherefores of Antibiotic

Resistance

Cameron R. Strachan and Julian Davies

$\beta$-Lactamases: A Focus on Current Challenges Robert A. Bonomo

Approved Glycopeptide Antibacterial Drugs: Mechanism of Action and Resistance Daina Zeng, Dmitri Debabov, Theresa L. Hartsell, et al.

Mechanism of Action and Resistance to

Daptomycin in Staphylococcus aureus and Enterococci

William R. Miller, Arnold S. Bayer and Cesar A. Arias

Polymyxin: Alternative Mechanisms of Action and Resistance

Michael J. Trimble, Patrik Mlynárcik, Milan Kolár, et al.

Topoisomerase Inhibitors: Fluoroquinolone

Mechanisms of Action and Resistance

David C. Hooper and George A. Jacoby

$\beta$-Lactams and $\beta$-Lactamase Inhibitors: An

Overview

Karen Bush and Patricia A. Bradford

Rifamycins, Alone and in Combination

David M. Rothstein

For additional articles in this collection, see http://perspectivesinmedicine.cshlp.org/cgi/collection/ 